\title{
Enhancement of Dopaminergic Differentiation in Proliferating Midbrain Neuroblasts by Sonic Hedgehog and Ascorbic Acid
}

\author{
Floriana Volpicelli, ${ }^{1}$ Claudia Consales, ${ }^{1}$ Massimiliano Caiazzo, ${ }^{1}$ Luca Colucci-D'Amato, ${ }^{1,2}$ \\ Carla Perrone-Capano ${ }^{1,3}$ and Umberto di Porzio ${ }^{1}$ \\ ${ }^{1}$ Institute of Genetics and Biophysics "A. Buzzati Traverso", CNR, Naples, Italy; ${ }^{2}$ Institute of \\ Endocrinology and Experimental Oncology, CNR, Naples, Italy; ${ }^{3}$ University of Catanzaro \\ "Magna Grecia", Pharmacobiology, Roccelletta di Borgia, CZ, Italy
}

SUMMARY

We analyzed the molecular mechanisms involved in the acquisition and maturation of dopaminergic (DA) neurons generated in vitro from rat ventral mesencephalon (MES) cells in the presence of mitogens or specific signaling molecules. The addition of basic fibroblast growth factor (bFGF) to MES cells in serum-free medium stimulates the proliferation of neuroblasts but delays DA differentiation. Recombinant Sonic hedgehog (SHH) protein increases up to three fold the number of tyrosine hydroxylase (TH)-positive cells and their differentiation, an effect abolished by anti-SHH antibodies. The expanded cultures are rich in nestin-positive neurons, glial cells are rare, all $\mathrm{TH}^{+}$neurons are $\mathrm{DA}$, and all $\mathrm{DA}$ and GABAergic markers analyzed are expressed. Adding ascorbic acid to bFGF/SHH-treated cultures resulted in a further five- to seven-fold enhancement of viable DA neurons. This experimental system also provides a powerful tool to generate DA neurons from single embryos. Our strategy provides an enriched source of MES DA neurons that are useful for analyzing molecular mechanisms controlling their function and for experimental regenerative approaches in DA dysfunction.

Reprint requests to: Dr. Floriana Volpicelli, IGB, CNR, Via P. Castellino 111, 80135 Naples, Italy; e-mail: volpicel@igb.cnr.it

\section{KEYWORDS}

Nurr1, tyrosine hydroxylase, primary cultures, bFGF, SHH.

\section{INTRODUCTION}

In mammals, three important contingents of dopaminergic (DA) neurons, consisting of the retrorubral nucleus, the substantia nigra, and the ventral tegmental area, are located in the ventral midbrain and form the nigrostriatal and the mesocortico-limbic DA pathways. These circuits regulate movement control, reward, and emotional behavior, as well as motivation. Degeneration of the ascending nigro-striatal pathway is associated with Parkinson's disease. Disturbance in the mesocortico-limbic system has been associated with schizophrenia, addictive behavioral disorders and attention-deficit hyperactivity disorder (ADHD) (Swanson, 1998; Hale, 2000). Considerable information has accumulated on the complex cellular and molecular mechanisms of midbrain patterning and DA phenotypic induction, development and maturation (di Porzio, 1999). In the midbrain, DA phenotype is determined by the action of two extracellular inducers: Sonic hedgehog (SHH) protein, a widespread morphogen produced by the floor plate and notochord, and fibroblast growth factor 8 (FGF8), produced by the 
isthmus (Hynes, 1995; Hynes, 1999; Wang, 1995). These factors activate cascades of other signaling molecules and transcription factors among which, Nurrl and Ptx3. The former is essential for the differentiation of DA neurons in both the ventral tegmental area and substantia nigra (Zetterstrom, 1997), whereas the latter is required for the development of SN but not ventral tegmental area DA neurons (Nunes, 2003; Smidt, 2004). Committed and determined DA neurons express the key genes necessary for DA neurotransmission, such as the $\mathrm{TH}$, vesicular monoamine transporter (VMAT2), and DA transporter (DAT) genes, at different times during development. Tyrosine hydroxylase, the rate-limiting enzyme in catecholamine biosynthesis, is expressed early during embryogenesis (E9) (di Porzio, 1990). The VMAT2, which concentrates biogenic amines in the dense core vesicles, is also expressed early in mesencephalic (MES) development. The DAT, a specific marker of DA neurons, is responsible for the high affinity uptake of DA, a function that appears at later stages of DA development when compared with other DA markers, both in vivo and in vitro (di Porzio, 1980; Perrone-Capano, 2000). The formation of midbrain DA circuits requires a proper matching between targets and presynaptic elements (Perrone-Capano, 2000; Zuddas, 1991). Striatal target neurons exert a beneficial and necessary effect on the maturation and function of presynaptic DA neurons, thereby modulating DAT and its function (di Porzio, 1980; Fiszman, 1991; Prochiantz, 1979; Perrone-Capano, 1996).

The DA neuronal culture technique is a useful tool to study molecular mechanisms involved in the development and maintenance of these neurons. Due to the fundamental role played by midbrain DA neurons in mammalian physiology and in human pathology, the generation of a large number of DA neurons has been explored by different approaches: expansion of committed DA neuron precursors (Studer, 1998; Ling, 1998; Potter, 1999), induction of immortalized neural cells to adopt a DA fate by gene transfection (Wagner, 1999), expansion and differentiation of embryonic and neural stem cells (Lee, 2000; Chung, 2002), transgenic approaches (Brodsky, 2003; Puelles, 2003).

Indeed, the question of whether DA neurons can interact with their proper target and form functional DA circuits, independently from their anatomical and functional origin, is still open because the interaction between embryonic and adult neurons in the nigrostriatal pathway is highly selective. For instance, only DA neurons obtained from MES, but not from other CNS regions, are able to restore function when grafted into mouse hosts with lesioned nigrostriatal system (Zuddas, 1990). This phenomenon supports the view that new approaches are needed to generate large number of DA neurons of MES origin.

In this study, we present a method to obtain DA neurons in high yield from ventral MES precursors. We expanded the neuroblasts by the action of the mitogen basic fibroblast growth factor (bFGF) and promoted their DA differentiation in the presence of specific signaling molecules.

\section{EXPERIMENTAL}

\section{Animals and dissections}

Timed pregnant Sprague-Dawley rats (Charles River Breeding Laboratories, Milan, Italy) were sacrificed in accordance with Society for Neuroscience guidelines and Italian law. The embryonic age (E) was determined by considering the day of insemination (as confirmed by vaginal plug) as day E0. Embryos from day 12 (E12) of gestation were quickly removed and placed in phosphate buffered saline (PBS), without calcium and magnesium, and supplemented with $33 \mathrm{mM}$ glucose. The ventral MES was carefully dissected under a stereoscope in sterile conditions and processed for cell cultures. Embryonic ventral MES were pooled before 
dissociation. A similar approach was applied to mouse embryos, with all conditions being the same except that the gestation stage was E11. In many cases cultures were also generated from single embryos.

\section{Cell cultures}

Cells were dissociated from embryonic rat ventral MES and cultured as previously described (di Porzio, 1980). Briefly, the tissues were dissected from E12 embryos and dissociated by mechanical trituration with a fire polished Pasteur pipette in culture medium (see below) and $0.01 \%$ pancreatic deoxyribonuclease (Sigma, Milan, Italy), centrifuged for $5 \mathrm{~min}$ at $700 \mathrm{rpm}$, suspended in plating medium, and counted.

Standard culture conditions: Cells were plated at a density of $125.000 / \mathrm{cm}^{2}$ (24-multiwell plates, Costar, Milan, Italy), in dishes coated with 15 micrograms $/ \mathrm{mL}$ of poly-D-Lysine (Sigma). Cells were grown in Neurobasal medium (Invitrogen, Milan, Italy) containing L-glutamine $(0.5 \mathrm{mM}$, Sigma), $7.5 \%$ fetal bovine serum (HyClone Laboratories Inc., Milan, Italy), $5 \%$ horse serum (Euroclone, Milan, Italy). Cytosine $\beta$-Darabinofuranoside, 5 micromolar, (AraC, Sigma) was added to the cultures after 3 days in vitro (DIV) to inhibit non-neuronal cell proliferation.

Expanded cultures: cells were dissociated from E12 MES as described above and plated at a density of $18.000 / \mathrm{cm}^{2}$ (24-multiwell plates), as above. Cells were grown as above in the absence of serum but with the addition of B27 supplement (Invitrogen), bFGF (20 ng/mL, Sigma) and the Nterminal fragment of the Sonic hedgehog (SHH) protein $(50 \mathrm{ng} / \mathrm{mL})$, and in some cultures ascorvic acid (Sigma, 200 micromolar) was added at 6 DIV. Half the medium was changed every 3 days; bFGF and SHH were withdrawn at various DIV, as indicated. AraC was never added.

\section{[3 H]-DA uptake}

$\left[{ }^{3} \mathrm{H}\right]$-DA uptake was performed as previously described (Prochiantz, 1979). Briefly, cultures were washed in PBS containing $33 \mathrm{mM}$ glucose, 1 $\mathrm{mM} \mathrm{CaCl} 2$ and $\mathrm{MgCl}_{2}$ and incubated for $15 \mathrm{~min}$ in the same buffer containing $50 \mathrm{nM}$ [7,8-3H]-DA (S.A. 40-60 Ci/ mmol, Amersham Biosciences, Milan, Italy) at $37^{\circ} \mathrm{C}$ or at $0^{\circ} \mathrm{C}$ (to obtain blank values). After three washes with cold PBS, cells were dissolved in $0.2 \mathrm{ml}$ of Triton X-100 (0.2\%) and $0.2 \mathrm{~N} \mathrm{NaOH}$, then neutralized with equimolar concentrations of $\mathrm{HCl}$ and counted in $5 \mathrm{~mL}$ Biodegradable counting scintillant (Amersham) in a Beckman liquid scintillation counter. The uptake was calculated by subtracting blank values from the amount of radioactivity accumulated at $37^{\circ} \mathrm{C}$. Cultures were always grown in at least triplicate samples for each experimental point and were processed separately.

\section{RT-PCR analyses}

RNA was extracted from single cultures, using the Tri-Reagent isolation system (Sigma) and following the manufacturer's instructions. Cultures for each experimental point were analyzed and processed separately. The yield and integrity of the RNA were determined by the spectrophotometric measurement of $\mathrm{A}_{260}$ and by agarose-gel electrophoresis, respectively. RT-PCR analyses were done as previously described (PerroneCapano, 1994; Pernas-Alonso 1999). Briefly, total RNA was treated with a DNA-free kit (Ambion Inc., Milan, Italy) to prevent false results from DNA contamination. Two micrograms of RNA were reverse transcribed using random hexanucleotides as primers (New England Biolabs Inc., Milan, Italy, 6 micromolar), $20 \mathrm{U}$ of Rnasin (Ambion) and $200 \mathrm{U}$ of Moloney-murine leukemia virus reverse transcriptase (Ambion). One twentieth of the reverse transcribed cDNA was 
amplified in a 25 microliters of reaction mixture containing AmpliTaq Gold DNA polymerase buffer (Applied Biosystems, Milan, Italy), $0.2 \mathrm{mM}$ dNTPs (Finnzymes OY, Espoo, Finland), 0.4 micromolar each primer, $1 \mathrm{U}$ AmpliTaq Gold DNA polymerase (Applied Biosystems) and 1 microcurie $\left[{ }^{32} \mathrm{P}\right] \mathrm{dCTP}(3000 \mathrm{Ci} / \mathrm{mmol}$, Amersham).

Different sets of primer pairs were used in the same reaction tube to co-amplify cDNA, together with primers for the hypoxantine-phosphoribosyltransferase (HPRT) gene, which is constantly expressed during CNS development, used as an internal standard (Steel, 1993). After a first denaturing step for $8 \mathrm{~min}$ at $95^{\circ} \mathrm{C}, \mathrm{PCR}$ amplification was performed for 27 cycles, organized as follows: $95^{\circ} \mathrm{C}$ for $30 \mathrm{sec} ; 56^{\circ} \mathrm{C}$ to $58^{\circ} \mathrm{C}$ for $30 \mathrm{sec} ; 72^{\circ} \mathrm{C}$ for $40 \mathrm{sec}$, followed by a final extension step $\left(72^{\circ} \mathrm{C}\right.$ for $\left.5 \mathrm{~min}\right)$. The number of cycles was experimentally chosen to fall into the exponential phase of the amplification reaction. The forward and reverse primers (MWGBiotech, Ebersberg, Germany) used are listed in Table 1, together with the length of amplified fragments. The specificity of PCR primers was determined by performing BLAST searches against the databases. Non-reverse-transcribed RNA templates and mock controls, always run in the PCR reactions, never produced amplification products. The identity of each amplified fragment was confirmed by size (see Table 1) and by digestion with restriction enzymes or by sequence analysis.

The $\left[{ }^{32} \mathrm{P}\right]$-labeled amplified products were separated by electrophoresis in $1.5 \%$ agarose gel, dried, and exposed to a Phosphorlmager screen. Quantization was achieved by integrating the volume areas of each fragment obtained from scanning the screens with a PhosphorImager apparatus (Molecular Dynamics, Sunnyvale, California, USA), equipped with ImageQuant software. The ratio between the yield of each amplified product and that of co-amplified HPRT allowed a relative estimate of mRNA levels
(Pernas-Alonso, 1999). Triplicate samples allowed statistical analysis (see below).

\section{Immunocytochemistry}

Tyrosine hydroxylase immunostaining: MES cell cultures were fixed for $30 \mathrm{~min}$ at room temperature in $4 \%$ paraformaldehyde in PBS, permeabilized for $15 \mathrm{~min}$ in PBS containing $0.1 \%$ Triton X-100 (unless indicated otherwise) and $10 \%$ normal goat serum, and incubated for $2 \mathrm{~h}$ at $24^{\circ} \mathrm{C}$ in PBS containing $10 \%$ normal goat serum and anti-TH antibody (1:200, Chemicon, Milan, Italy). Mesencephalic cell cultures were stained according to standard avidin-biotin immunocytochemistry procedures (Vectastain Elite, Vector Laboratories, Burlingame, California, USA), using a peroxidase substrate kit (DiAaminoBenzidine). Control cells were incubated in the same solutions without primary antibodies and subsequently processed as above. The TH positive cells were counted in each well of a Lab-Tek chamber slide (Nunc, VWR International, Milan), using an eyepiece grid. Three culture wells were analyzed in each experiment for each experimental condition. The length of $\mathrm{TH}^{+}$neurites was analyzed counting randomly 3 points in each well of a Lab-Tek chamber slide; the number of neurites for $\mathrm{TH}^{+}$neurons was evaluated counting, always in each well of a Lab-Tek chamber, the number of neurites in 20 random neurons.

\section{Sonic hedgehog purification}

Escherichia coli strain BL21 was transformed with a plasmid pGEX-N (gift of P. Beachy), which expresses the $\mathrm{N}$-terminal fragment of mouse $\mathrm{SHH}$, and induced with isopropyl-beta-D-thiogalactopyranoside (IPTG). Cells were lysed and cleared lysates were bound to glutathione-conjugated Sepharose beads (Pharmacia). The bound fusion protein was cleaved with a mass of thrombin (Sigma) equivalent to $1 \%$ the mass of fusion 


\section{TABLE 1}

Primers nucleotide sequence (5'-3') used for RT-PCR experiments

\begin{tabular}{|l|l|l|l|l|l|}
\hline c-RET & $\begin{array}{l}\text { F. CGGCTGCATGAGAATGACTGGA } \\
\text { R. CAAAGCCTCCAGCACATACTTC }\end{array}$ & $494 \mathrm{bp}$ & Nestin & $\begin{array}{l}\text { F. CGCTCGGGAGTGTCGCTTAGA } \\
\text { R. GCCTCCAGCAGAGTCCTGTAT }\end{array}$ & $273 \mathrm{bp}$ \\
\hline DAT & $\begin{array}{l}\text { F. CGTGGGACCAATGTCTTCAGTG } \\
\text { R. ATGGTGAAGGAGGAGAAGAAGT }\end{array}$ & $498 \mathrm{bp}$ & NFH & $\begin{array}{l}\text { F. AGCCTGAGGAGAAGCCCAAA } \\
\text { R. CGTAGCGTTCAGCATACATC }\end{array}$ & $453 \mathrm{bp}$ \\
\hline EP10 & $\begin{array}{l}\text { F. GCTGGAAGGCATGGAAGGTT } \\
\text { R. AGCCCCATCACCGTAGCAAC }\end{array}$ & $242 \mathrm{bp}$ & NFL & $\begin{array}{l}\text { F. ACCTCTCCGCCGCTCTCAAG } \\
\text { R. TCTCCTCGACCTCTGTCTGCTCT }\end{array}$ & $613 \mathrm{bp}$ \\
\hline GAD65 & $\begin{array}{l}\text { F. GGCTCTGGCTTTTGGTCCTTC } \\
\text { R. TGCCAATTCCCAATTATACTCTTGA }\end{array}$ & $437 \mathrm{bp}$ & NFM & $\begin{array}{l}\text { F. GAAATGGAAGAAACCCTCACA } \\
\text { R. CCGGCCTTGGCCTCTGGTTTTGG }\end{array}$ & $474 \mathrm{bp}$ \\
\hline GAD67 & $\begin{array}{l}\text { F. GACCGACTTCTCCAACCTGTT } \\
\text { R. TCCCATCACCATCTTTATTTG }\end{array}$ & $308 \mathrm{bp}$ & Nurr1 & $\begin{array}{l}\text { F. CGCGTCGCAGTTGCTTGACAC } \\
\text { R. TTGCCTGGAACCTGGAATAGT }\end{array}$ & $449 \mathrm{bp}$ \\
\hline GFAP & $\begin{array}{l}\text { F. GCTGGAGGTGGAGAGGGACA } \\
\text { R. TGGCGGCGATAGTCGTTAGC }\end{array}$ & $456 \mathrm{bp}$ & TH & $\begin{array}{l}\text { F. TGTCACGTCCCCAAGGTTCAT } \\
\text { R. GGGCAGGCCGGGTCTCTAAGT }\end{array}$ & $276 \mathrm{bp}$ \\
\hline HPRT & $\begin{array}{l}\text { F. CCTGCTGGATTACATTAAAGCACTG } \\
\text { R.CCTGAAGTACTCATTATAGTCAAGG }\end{array}$ & $370 \mathrm{bp}$ & VMAT2 & $\begin{array}{l}\text { F. ATCCAGACCACCAGACCAGAG } \\
\text { R. CCCCATCCAAGAGCACCAAGG }\end{array}$ & $616 \mathrm{bp}$ \\
\hline
\end{tabular}

The table shows the forward (F.) and reverse (R.) primer sequences with length of amplified fragments (bp) used in RTPCR for the following genes: tyrosine kinase receptor Ret (c-Ret), dopamine transporter (DAT), glutamate acid decarboxylase 65 (GAD65) and 67 (GAD67), the embryonic truncated form of GAD67 (EP10), glial fibrillary acidic protein (GFAP), hypoxantine-phosphoribosyl-transferase (HPRT), Nestin, high neurofilament (NFH), light neurofilament (NFL), medium neurofilament (NFM), Nurrl, tyrosine hydroxylase (TH), vesicular monoamine transporter (VMAT2).

protein in $10 \mathrm{mM}$ Tris- $\mathrm{HCl}(\mathrm{pH} 7.5), 150 \mathrm{mM}$ $\mathrm{NaCl}, 2.5 \mathrm{mM} \mathrm{CaCl}_{2}$. The protein released from the beads was batch adsorbed to anti-thrombinagarose (Sigma). The SHH protein was purified from this supernatant by adsorption to heparinagarose (Pharmacia) in PBS containing $1 \mathrm{mM}$ DTT (Sigma) followed by elution in PBS containing $550 \mathrm{mM} \mathrm{NaCl}, 1 \mathrm{mM}$ DTT, $10 \%$ glycerin (Sigma). The concentration of SHH was determined by Bradford assay (Bio-Rad). The SHH product was detected as a single band of 22
$\mathrm{kDa}$ on SDS-PAGE stained with Coomassie blue, indicating a purity greater than $95 \%$. The purified protein was aliquot and stored at $-80^{\circ} \mathrm{C}$ until use.

\section{Statistical analysis}

At least triplicate samples were used in all the experiments, thus allowing statistical analysis. Analysis of variance was carried out, followed by post hoc comparison (ANOVA, Scheffè F-test). Data were expressed as mean \pm SEM. 


\section{RESULTS}

\section{Expanded MES DA cultures}

Establishment of cultures. We used ventral MES dissected from E12 rat, a time when a large number of DA precursors are present (di Porzio, 1990) and still proliferating, to study the mitogenic effect of bFGF on dissociated MES cells in cultures. Alternatively, mouse E11 embryos were used. Embryonic ventral MES from various litters were pooled before dissociation or used to generate cultures from single embryos. Dissociated cells were plated at low density $\left(18000 \mathrm{cells} / \mathrm{cm}^{2}\right)$, to avoid differentiating effects caused by cell-cell interactions, in serum-free medium to prevent glial cell proliferation. We observed that adding bFGF $(20 \mathrm{ng} / \mathrm{mL})$ at the beginning of the culture was mandatory to ensure the proliferation of E12 MES cells (Fig. 1). During the first day in vitro, the cells adopted a spherical morphology and after 3 days formed small clusters, which already extended some neurites as previously described by Bouvier and Mytilineou (1995). In our conditions, a few neurons present in these clusters showed differentiated features of the DA phenotype, as monitored by anti-TH immunocytochemistry (Fig. 2B). When bFGF was withdrawn, however, we observed a clear neuronal differentiation of most cells and obtained an increase in the number of $\mathrm{TH}^{+}$cells. The cultures were treated with the amino-terminal recombinant fragment of SHH (50 $\mathrm{ng} / \mathrm{mL}$ ) to further enhance DA differentiation.

We tested various combinations of addition/ withdrawal of bFGF and SHH at different DIV. The cultures, which we called expanded MES DA cultures, were analyzed 9 to 12 days after plating. As shown in Fig. $2 \mathrm{~A}$, the number of $\mathrm{TH}^{+}$cells stimulated for 9 DIV with bFGF increased, compared with controls, by 1.5 fold when SHH was added at $6 \mathrm{DIV}$, by 2-fold when bFGF was subtracted after 6 DIV, by 2.5 fold when the cells were stimulated for 6 DIV with bFGF and subsequently SHH was added for 3 more DIV. A greater number of $\mathrm{TH}^{+}$cells were obtained when SHH was added together with bFGF to the medium at the time of plating and both factors were withdrawn after 6 DIV. To verify whether the increased number of $\mathrm{TH}^{+}$cells was selectively due to SHH added to the cultures, neutralizing antibodies were used to block its activity. On average, a saturating dose of SHH $(50 \mathrm{ng} / \mathrm{mL})$ at least doubled the number of $\mathrm{TH}^{+}$neurons, whereas the presence of a five-fold molar excess of antiSHH antibodies completely inhibited this response (Volpicelli, 2004). To verify if the addition of SHH might have a trophic effect on the expanded MES cultures, we measured the length, area, and number of neurites $/ \mathrm{TH}^{+}$cells. No significant difference was found between bFGF-stimulated cultures with or without SHH (data not shown).

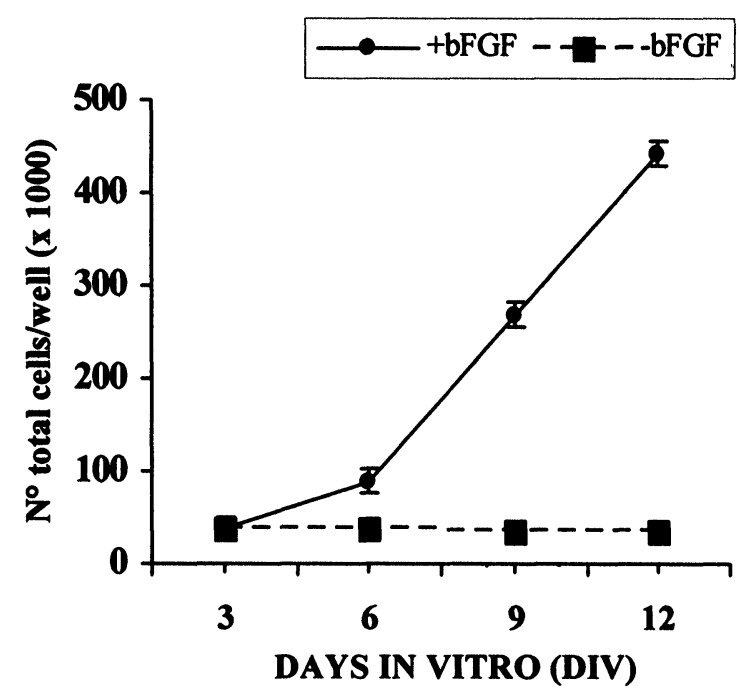

Fig. 1: Expansion of mesencephalic precursors in vitro. Comparison of bFGF treated (+bFGF) and control cultures (-bFGF) at different days in vitro (DIV). Every value represent the mean $+/-$ SEM of triplicate samples for each experimental point. 
Characterization of expanded MES DA cultures. We adopted the condition that induced the differentiation of a greater number of $\mathrm{TH}^{+}$cells $(6$ DIV of bFGF and SHH stimulation) to study and characterize by gene expression analyses and functional assays, further DA differentiation occurring in the expanded MES cultures after withdrawal of bFGF and SHH (at 9-12 DIV).

The expanded MES DA cultures, analyzed after 12 DIV, contained neural precursors, as shown by the expression of the nestin gene, and developing or mature neurons, which expressed light and medium (NFL, NFM) but not high (NFH) neurofilament subunits. In different culture conditions $( \pm \mathrm{bFGF} ; \pm \mathrm{SHH})$, the expression of NFL and NFM genes was not significantly different (Fig. 3). In the cultures treated for 6 days with bFGF or with bFGF and SHH, NFL gene expression was increased about two-fold when compared with cells plated at high density in the presence of serum (see Experimental section), whereas NFM gene expression did not vary in the two conditions.

To evaluate the presence and the proliferation of glial cells in MES expanded cultures, we analyzed the gene expression of glial fibrillary

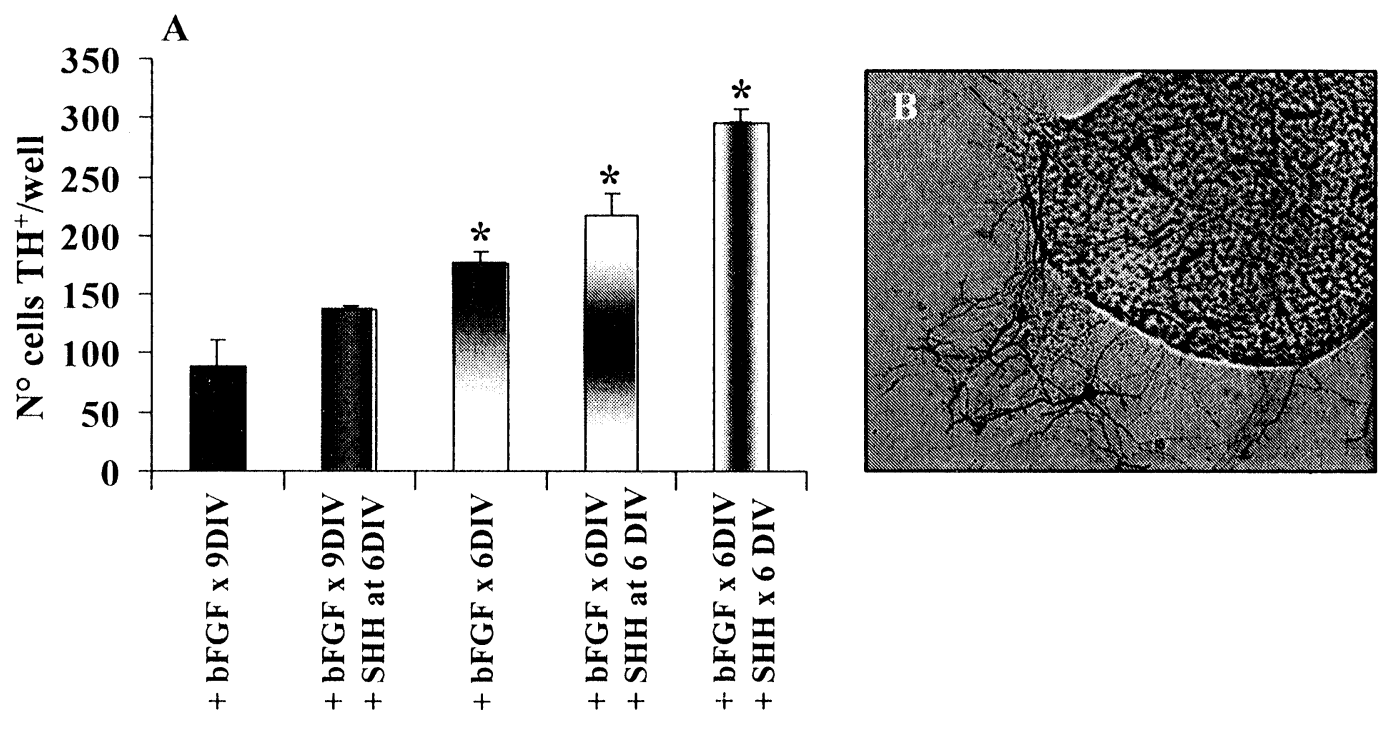

Fig. 2: Characterization of expanded MES DA cultures. (A): Number of $\mathrm{TH}^{+}$cells in $9 \mathrm{DIV}$ cultures treated with bFGF $(20 \mathrm{ng} / \mathrm{ml})$ for 9 DIV (+bFGF x 9 DIV), with bFGF for 9 DIV and addition of SHH $(50 \mathrm{ng} / \mathrm{ml})$ at $6 \mathrm{DIV}$ (+bFGF $\times 9$ DIV, +SHH at 6 DIV), with bFGF for 6 DIV (+bFGF $\times 6$ DIV), with bFGF for 6 DIV and subsequent addition of SHH at 6 DIV (+bFGF $\times 6$ DIV, + SHH at 6 DIV) or plated in the presence of both bFGF and SHH which are subtracted at 6 DIV (+bFGF $\times 6$ DIV, +SHH $\times 6$ DIV). The bars represent the mean $+/$ - SEM of triplicate samples for each experimental point. Asterisks represent $p<0.01$ when compared to cultures treated with bFGF for 9 DIV (ANOVA, Scheffè F-test). (B): TH-immunoreactive neurons at 9 DIV, after stimulation with bFGF and SHH for 6 DIV. 
acidic protein (GFAP), the intermediate filament of astrocytes. The GFAP gene was expressed at very low levels at any time in expanded cultures, unless serum was added after 6 days of bFGF stimulation. In this condition, GFAP gene expression was greater than that observed in standard conditions in serum-supplemented growth medium because in the latter, Ara $\mathrm{C}$ was added 3 days after plating to avoid the overgrowth of glial cells (Fig. 3).

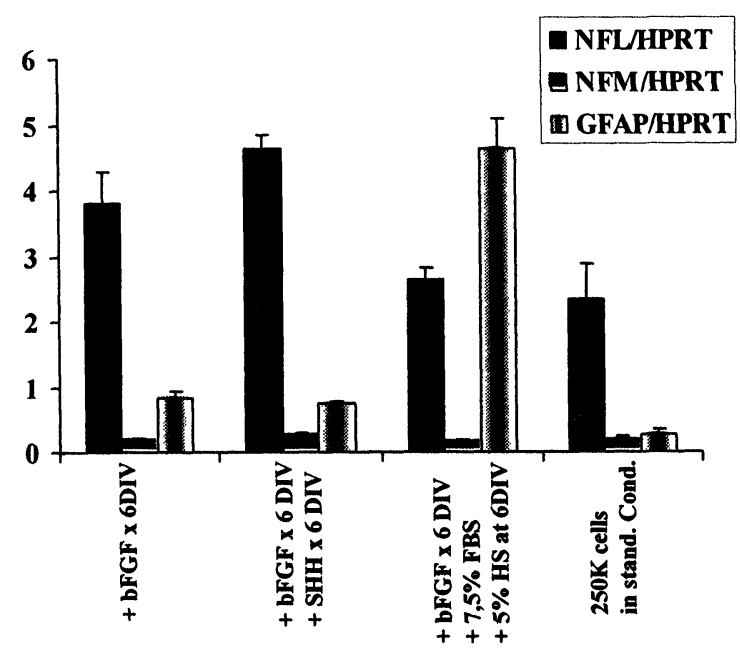

Fig. 3: Gene expression in expanded and standard mesencephalic cultures. The diagrams show the relative quantization (mean +/- SEM) of the intermediate filaments light neurofilament (NFL), medium neurofilament (NFM) and glial fibrillary acidic protein (GFAP) amplified product compared to that of the hypoxanthine phosphoribosyl transferase (HPRT, internal standard), assessed by RT-PCR. Data are expressed as ratio NFL/HPRT, NFM/HPRT, GFAP/HPRT. Expanded MES cultures were analyzed at 12 DIV after the treatment with either bFGF for 6 DIV, or bFGF and SHH for the first $6 \mathrm{DIV}$, or bFGF for the first 6 DIV and consequently addition of fetal bovine serum (FBS) and horse serum (HS), or plated in standard conditions (see Experimental section).
As GABAergic neurons constitute an important contingent of ventral MES neurons, we analyzed the expression of key genes involved in GABA biosynthesis to evaluate whether the GABAergic phenotype could also be influenced by treatment with $\mathrm{bFGF}$ and $\mathrm{SHH}$. As expected, the expression of glutamate acid decarboxylase GAD65, GAD67, and EP10 genes (the embryonic truncated form of GAD67) was detectable but was not significantly different in the different culture conditions tested ( \pm bFGF; \pm SHH; data not shown).

In addition, expanded MES DA cultures expressed all the DA genes analyzed, such as $\mathrm{TH}$, DAT, Nurr1, VMAT2 (Volpicelli, 2004), and the tyrosine kinase receptor Ret (c-Ret, Volpicelli, 2004). Different culture conditions ( \pm bFGF; $\pm \mathrm{SHH})$ did not influence the mRNA profiles of these genes (Fig. 4A).

Recent findings have demonstrated that ascorbic acid (AA) increases the survival of $\mathrm{TH}^{+}$ MES precursors (Yan, 2001; Lee, 2003). Thus, we tested the possibility of enriching $\mathrm{TH}^{+}$cells in our expanded MES cultures using a similar treatment. The addition of AA $(200 \mu \mathrm{M})$ for three days after six DIV of stimulation with bFGF and SHH led to a further four-to seven-fold increase in the number of $\mathrm{TH}^{+}$cells, when compared with cultures treated for $6 \mathrm{DIV}$ with $\mathrm{bFGF} / \mathrm{SHH}$ alone (Fig. 5A, 5B). This increase was paralleled by a seven-fold or greater increase in TH mRNA and a two-fold increase in DAT mRNA (Fig. 4B). The effect on the TH mRNA increase was evident only when AA was added following bFGF and SHH withdrawal.

To characterize the neuronal maturation of expanded MES cultures, we tested the ability of these cells to incorporate $\left[{ }^{3} \mathrm{H}\right]-\mathrm{DA}$ by high affinity uptake, a function expressed only in differentiated embryonic DA neurons.

As shown in Fig. 6A, at 12 DIV the [ $\left.{ }^{3} \mathrm{H}\right]-\mathrm{DA}$ uptake significantly increased after bFGF was withdrawn from the medium after 6 DIV, when compared with cultures grown for 9 DIV in 

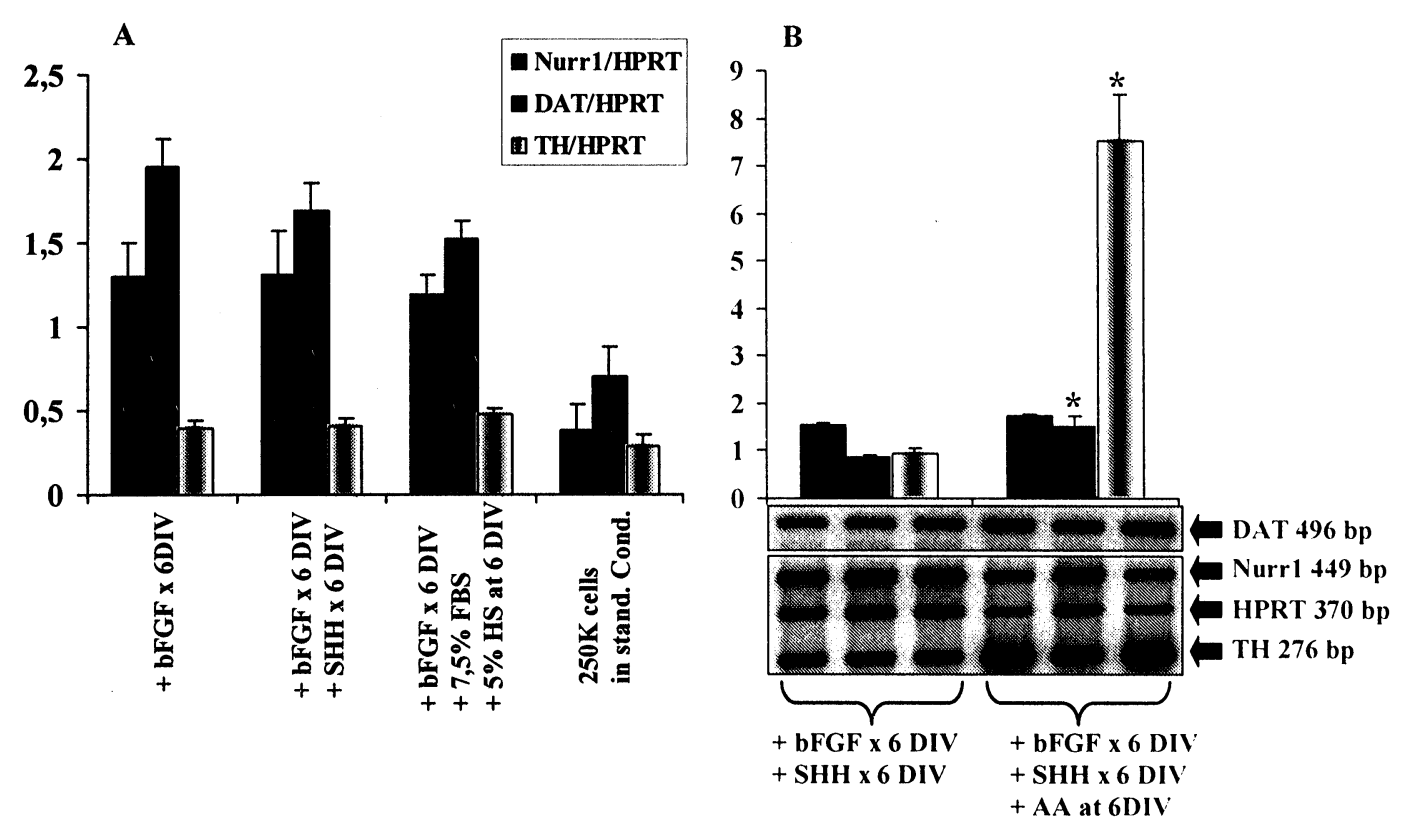

Fig. 4: Dopaminergic gene expression in expanded and standard mesencephalic cultures. The diagrams show the relative quantization (mean +/-SEM) of Nurrl, dopamine transporter (DAT) and tyrosine hydroxylase (TH) amplified product, assessed by RT-PCR, compared to that of the hypoxanthine phosphoribosyl transferase (HPRT, internal standard). Data are expressed as ratio Nurr1/HPRT, DAT/HPRT, TH/HPRT. (A): Expanded MES cultures were analyzed at 12 DIV after the treatment with bFGF for 6 DIV, or bFGF and SHH for the first $6 \mathrm{DIV}$, or bFGF for the first 6 DIV and consequently addition of fetal bovine serum (FBS) and horse serum (HS), or plated in standard conditions (see Experimental section). (B): Expanded MES cultures were analyzed at 9 DIV after treatment with bFGF and SHH for the first 6 DIV and subsequent administration of ascorbic acid (AA) for three more days. The gel in the inset shows triplicate samples for each experimental condition of the co-amplified DAT, Nurr1, HPRT, and TH fragments. The size of the amplified products is shown on the right in base pairs (bp). Asterisks represent $p<0.01$ when compared to cultures without AA (ANOVA, Scheffe Ftest).

the presence of bFGF. Interestingly, $\left[{ }^{3} \mathrm{H}\right]-\mathrm{DA}$ uptake was not influenced by the presence of SHH. The addition of AA inducca a modest further increase in DA uptake (Fig. 6B).

The reversal of total $\left[{ }^{3} \mathrm{H}\right]-\mathrm{DA}$ uptake by a selective uptake inhibitor of DAT (Volpicelli, 2004) indicates that virtually all $\mathrm{TH}^{+}$cells detected in the expanded MES cultures were DA neurons.

\section{DISCUSSION}

Because of the high impact of neurological diseases, the development of in vitro systems for generating embryonic neurons has been an important goal of many laboratories in recent years. Such approaches are aimed at studying the molecular and cellular events involved in wide 

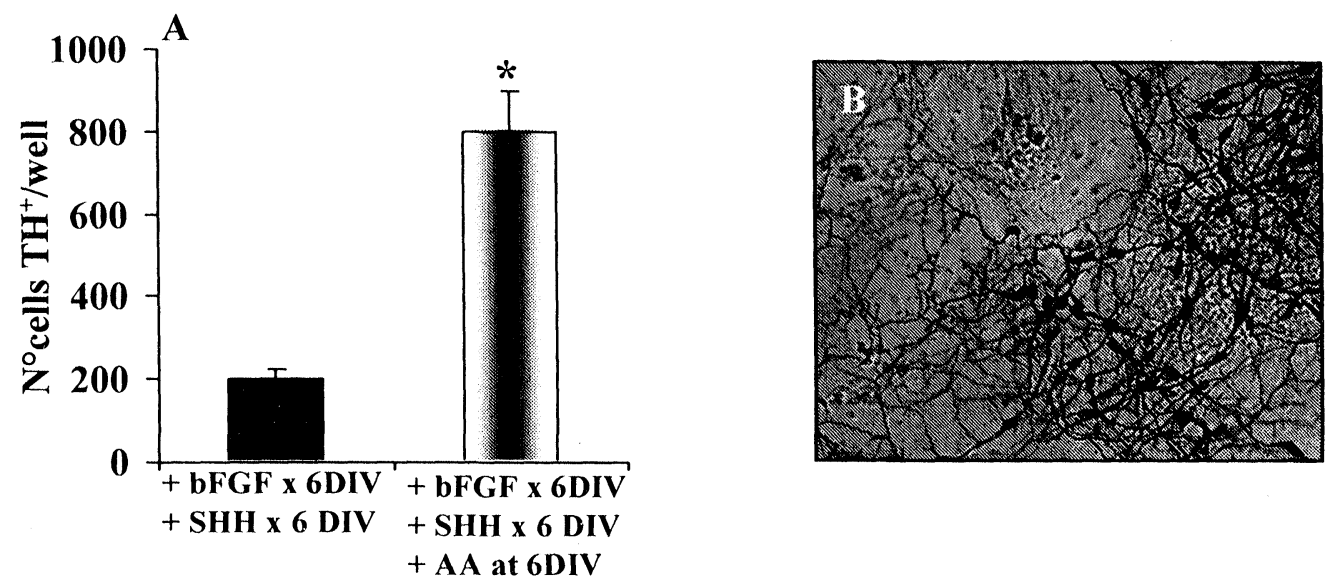

Fig. 5: The role of ascorbic acid. (A): Cells treated with $200 \mu \mathrm{M}$ ascorbic acid (AA) at 6 DIV after the stimulation with bFGF and SHH for 1 to 6 DIV. The bars represent the mean +/- SEM of triplicate samples for each experimental point. Asterisks represent $p<0.01$ when compared to cultures without AA (ANOVA, Scheffe $F_{\cdots}$ test). (B): TH-immunoreactive neurons at 9 DIV, after stimulation with bFGF and SHH for 6 DIV and subsequent addition of AA for 3 DIV.

$\mathbf{A}$

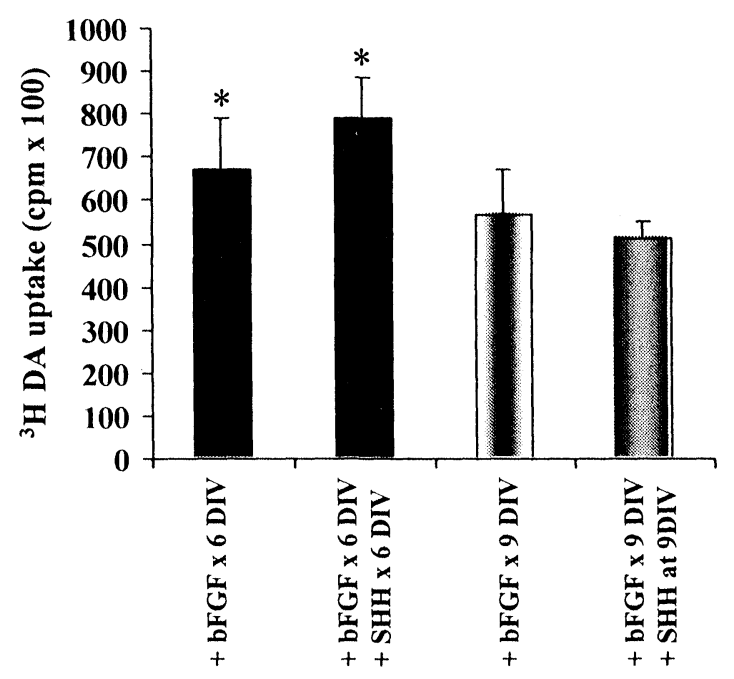

B

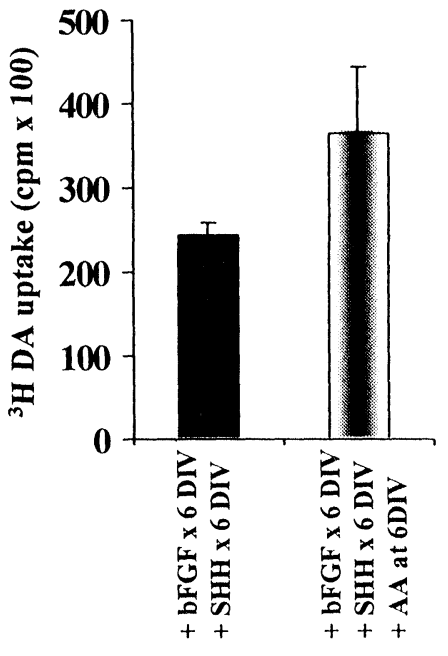

Fig. 6: $\left[{ }^{3} \mathrm{H}\right]$-dopamine uptake in expanded MES cultures. (A): $\left[{ }^{3} \mathrm{H}\right]$-dopamine uptake at 12 DIV in expanded MES culture treated with bFGF for the first 6 DIV, or bFGF and SHH for the first 6 DIV, or bFGF for 9 DIV, or bFGF for 9 DIV and addition of SHH at 9 DIV. The bars represent the mean $+/$ - SEM of triplicate samples for each experimental point. Asterisks represent $p<0.01$ when compared to cultures in presence of bFGF for 9 DIV (ANOVA, Scheffe F-test). (B): $\left[{ }^{3} \mathrm{H}\right]$-dopamine uptake at 9 DIV in expanded MES cultures treated with bFGF and SHH for the first 6 DIV and subsequent administration of AA for 3 DIV. 
spread CNS pathologies involving specific neuronal populations and at replacing the degenerated endogenous neurons. Identifying the conditions required for the induction of neural cells and the activation of DA-specific developmental patterns and phenotypes can be particularly useful for treating the progressive neurodegenerative disorder Parkinson's disease and for studying alterations that can shed light in developmental disorders like ADHD.

Here we report a new method to enhance midbrain DA differentiation and to increase the number of MES DA neurons in primary cultures by exploiting the mitogenic effect of $b F G F$ and the inductive action of SHH protein. Administering AA further enhances the number of DA neurons. Thus, our conditions enable an increase of DA neurons. Interestingly, the DA neuron inducer $\mathrm{SHH}$, which in our conditions mimics in vitro its in vivo effects, as described by Hynes (1995), does not seem to behave as a trophic factor for DA neurons in vitro, as described by Miao (1997). This difference could be due to different culture conditions and to the developmental stages of DA cells.

The expression of genes encoding for neuronal intermediate filaments shows that NFL and NFM but not NFH are present in the expanded cultures. The results indicate that still developing neurons populate our expanded cultures, in agreement with previous data from our and other laboratories, showing that NFH appears in various CNS regions late in development (Pernas-Alonso, 1996; Julien, 1986).

Interestingly, the addition of bFGF and SHH to expand MES DA cultures does not induce glial proliferation, as assessed by GFAP gene expression, although it does not inhibit the survival of glioblasts, which remains quiescent in our culture conditions. On the whole, the combined action of bFGF and SHH increases the number of DA neurons but does not seem to influence neuronal maturation, which takes place after the withdrawal of bFGF and $\mathrm{SHH}$, as shown by the presence of DA markers (Nurr1, TH, DAT, cRet, VMAT2).

Differently, a maturation effect parallels the increased number of DA neurons observed in our cultures following AA administration, as shown by increased TH and DAT mRNA, not observed in cultures treated only with bFGF and SHH. Indeed, whether AA acts through an inductive or a selective mechanism remains to be established. A similar effect of AA on bFGF-stimulated DA neuroblasts was observed by Mckay and collaborators (Yan, 2001) during cell passages, suggesting that most of the effect observed by these authors could be due to an increased survival of DA neurons.

The expanded primary cultures described here provide several advantages. The expansion of neuroblasts in the proliferative phase and the enrichment in DA neurons can reduce the amount of original embryonic DA neurons that is needed for experimental or therapeutic grafting. The possibility of protracting the culture period provides an opportunity to generate cultures enriched in DA neurons at various differentiation steps. The controlled in vitro generation of DA neurons thus offers an ideal tool to identify and to investigate the function of still undetected genes implicated in the differentiation of DA neurons. Finally, our approach offers the possibility of generating expanded cultures from the ventral MES of single embryos at early embryonic stages, thus allowing the study of DA development and its dysfunction from spontaneously mutated or genetically modified animal models, even when they do not reach birth. In this perspective, expanded DA primary cultures from single embryos offer a useful system for studying the molecular events involved in certain DA neuropathologies like ADHD. As ADHD is a pathology that mostly strikes males, expanded primary cultures from single embryos could be very useful for studying possible sex difference in developing DA neurons and for testing the molecular effects of drugs used in ADHD tre atment. 
In conclusion, we have shown that it is possible to enrich MES DA neurons in vitro by the combined action of specific mitogens, morphogens, and other inducer agents. This system is highly appropriate to study molecular and cellular mechanisms of the differentiation, function, and survival of DA neurons.

\section{ACKNOWLEDGMENTS}

This work was supported by CEE QLRT-200101000-GDNF, MURST/MIUR Cofin. 2001 (N. 2001052911_002) and 2003 (N. 2003059030_002), MURST cluster 02 to IIGB, FIRB Neuroscienze RBNE01WY7P and ISS National Stem Cell Program. We thank Prof. P.A. Beachy (Johns Hopkins, Baltimore, USA) for the SHH producing cells, Dr. Davide Viggiano (II University of Naples, Italy) for his help in some experiments, the Developmental Studies Hybridoma Bank for the anti-SHH (5E1 antibody) (Iowa City, Iowa, USA), M. Terracciano and B. Esposito (IGB, Naples, Italy) for technical help.

\section{REFERENCES}

Bouvier MM, Mytilineou C. 1995. Basic fibroblast growth factor increases division and delays differentiation of dopamine precursors in vitro. $\mathrm{J}$ Neurosci 15: 7141-7149.

Brodski C, Weisenhorn DM, Signore M, Sillaber I, Oesterheld M, Broccoli V, et al. 2003. Location and size of DA and serotonergic cell populations are controlled by the position of the midbrainhindbrain organizer. J Neurosci 23: 4199-4207.

Chung S, Sonntag KC, Andersson T, Bjorklund LM, Park JJ, Kim DW, et al. 2002. Genetic engineering of mouse embryonic stem cells by Nurrl enhances differentiation and maturation into dopaminergic neurons. Eur J Neurosci 16: 1829-1838.

di Porzio U, Daguet MC, Glowinski J, Prochiantz A. 1980. Effect of striatal cells on in vitro maturation of mesencephalic DA neurons grown in serum-free conditions. Nature 288: 370-373. di Porzio U, Zuddas A, Cosenza-Murphy DB, Barker JL. 1990. Early appearance of tyrosine hydroxylase immunoreactive neurons in the mesencephalon of mouse embryos. Int J Dev Neurosci 8: 523-532.

di Porzio U, Perrone-Capano C, Pernas-Alonso R. 1999. Development of Midbrain Dopaminergic Neurons. Austin, Texas, USA: Landes Company, 37-55.

Hale TS, Hariri AR, McCracken JT. 2000. Attentiondeficit/hyperactivity disorder: perspectives from neuroimaging. Ment Retard Dev Disabil Res Rev 6: 214-219.

Hynes M, Porter JA, Chiang C, Chang D, TessierLavigne M, Beachy PA, et al. 1995. Induction of midbrain dopaminergic neurons by Sonic hedgehog. Neuron 15: 35-44.

Hynes M, Rosenthal A. 1999. Specification of dopaminergic and serotonergic neurons in the vertebrate CNS. Curr Opin Neurobiol 9: 26-36.

Julien JP, Meyer D, Flavell D, Hurst J, Grosveld F. 1986. Cloning and developmental expression of the murine neurofilament gene family. Brain Res 387 : 243-250.

Lee JY, Koh HC, Chang MY, Park CH, Lee YS, Lee SH. 2003. Erythropoietin and bone morphogenetic protein 7 mediate ascorbate-induced dopaminergic differentiation from embryonic mesencephalic precursors. Neuroreport 14: 1401-1404.

Lee SH, Lumelsky N, Studer L, Auerbach JM, McKay RD. 2000. Efficient generation of midbrain and hindbrain neurons from mouse embryonic stem cells. Nat Biotechnol 18: 675-679.

Ling ZD, Potter ED, Lipton JW, Carvey PM. 1998. Differentiation of mesencephalic progenitor cells into dopaminergic neurons by cytokines. Exp Neurol. 149: 41 1-423.

Miao N, Wang M, Ott JA, D'Alessandro JS, Woolf TM, Bumcrot DA, et al. 1997. Sonic hedgehog promotes the survival of specific CNS neuron populations and protects these cells from toxic insult in vitro. J Neurosci 17: 5891-5899.

Nunes I, Tovmasian LT, Silva RM, Burke RE, Goff SP. 2003. Pitx3 is required for development of substantia nigra dopaminergic neurons. Proc Natl Acad Sci USA 100: 4245-4250.

Pernas-Alonso R, Schaffner AE, Perrone-Capano C, Orlando A, Morelli F, Hansen CT. et al. 1996. Early upregulation of medium neurofilament gene expression in developing spinal cord of the wobbler mouse mutant. Brain Res Mol Brain Res 38: 267-275.

Pernas-Alonso R, Morelli F, di Porzio U, Perrone- 
Capano C. 1999. Multiplex semi-quantitative reverse transcriptase-PCR of low abundance neuronal mRNAs. Brain Res Prot 4: 395-406.

Perrone-Capano C, Tino A, di Porzio U. 1994. Target cells modulate dopamine transporter gene expression during brain development. Neuroreport 5: 1145-1148.

Perrone-Capano C, Tino A, Amadoro G, PernasAlonso R, di Porzio U. 1996. Dopamine transporter gene expression in rat mesencephalic dopaminergic neurons is increased by direct interaction with target striatal cells in vitro. Brain Res Mol Brain Res 39: 160-166.

Perrone-Capano C, Da Pozzo P, di Porzio U. 2000. Epigenetic cues in midbrain dopaminergic neuron development. Neurosci Biobehav Rev 24: 119-125.

Potter ED, Ling ZD, Carvey PM. 1999. Cytokineinduced conversion of mesencephalic-derived progenitor cells into dopamine neurons. Cell Tissue Res 296: 235-246.

Prochiantz A, di Porzio U, Kato A, Berger B, Glowinski J. 1979. In vitro maturation of mesencephalic dopaminergic neurons from mouse embryos is enhanced in presence of striatal target cells. Proc Natl Acad Sci USA 76: 5387-5391.

Puelles E, Acampora D, Lacroix E, Signore M, Annino A, Tuorto F, et al. 2003. Otx dosedependent integrated control of antero-posterior and dorso-ventral patterning of midbrain. Nat Neurosci 6: 453-460.

Smidt MP, Smits SM, Bouwmeester H, Hamers FPT, van der Linden AJA, Hellemons AJCGM, et al. 2004. Early developmental failure of substantia nigra dopamine neurons in mice lacking the homeodomain gene Pitx3. Development 131: 1145-1155.
Steel MC, Buckley NJ. 1993. Differential regulation of muscarinic receptor mRNA levels in neuroblastoma cells by chronic agonist exposure: a comparative polymerase chain reaction study. Mol Pharmacol 43: 694-701.

Studer L, Tabar V, McKay RD. 1998. Transplantation of expanded mesencephalic precursors leads to recovery in parkinsonian rats. Nat Neurosci 1:290 295.

Swanson J, Castellanos FX, Murias M, LaHoste G, Kennedy J. 1998. Cognitive neuroscience of attention deficit hyperactivity disorder and hyperkinetic disorder. Curr Opin Neurobiol 8: 263-271.

Volpicelli F, Perrone-Capano C, Da Pozzo P, ColucciD'Amato L, di Porzio U. 2004. Modulation of nurrl gene expression in mesencephalic dopaminergic neurones. J Neurochem 88: 1283-1294.

Wagner J, Akerud P, Castro DS, Holm PC, Canals JM, Snyder EY, et al. 1999. Induction of midbrain dopaminergic phenotype in Nurrl-overexpressing neural stem cells by type 1 astrocytes. Nat Biotechnol 17: 653-659.

Wang L, Pitts DK. 1995. Ontogeny of nigrostriatal dopamine neuron autoreceptors: iontophoretic studies. J Pharmacol Exp Ther 272: 164-176.

Yan J, Studer L, McKay RD. 2001. Ascorbic acid increases the yield of dopaminergic neurons derived from basic fibroblast growth factor expanded mesencephalic precursors. J Neurochem 76: 307-311.

Zetterstrom RH, Solomin L, Jansson L, Hoffer BJ, Olson L, Perlmann T. 1997. Dopamine neuron agenesis in Nurr1-deficient mice. Science 276: 248-50.

Zuddas A, Corsini GU, Barker JL, Kopin IJ, di Porzio U. 1991. Specific reinnervation of lesioned mouse striatum by grafted mesencephalic dopaminergic neurons. Eur J Neurosci 3: 72-85. 

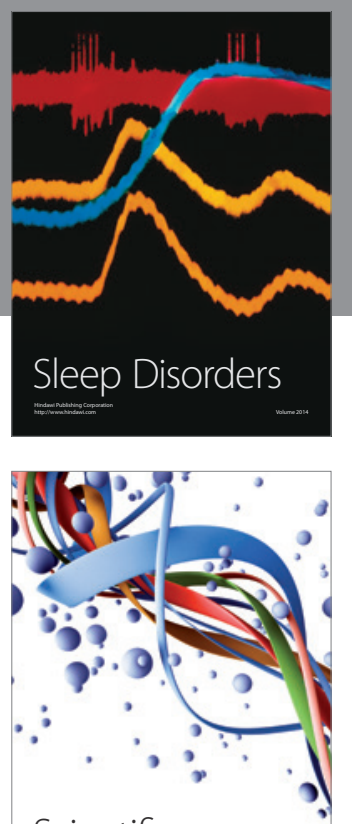

Scientifica
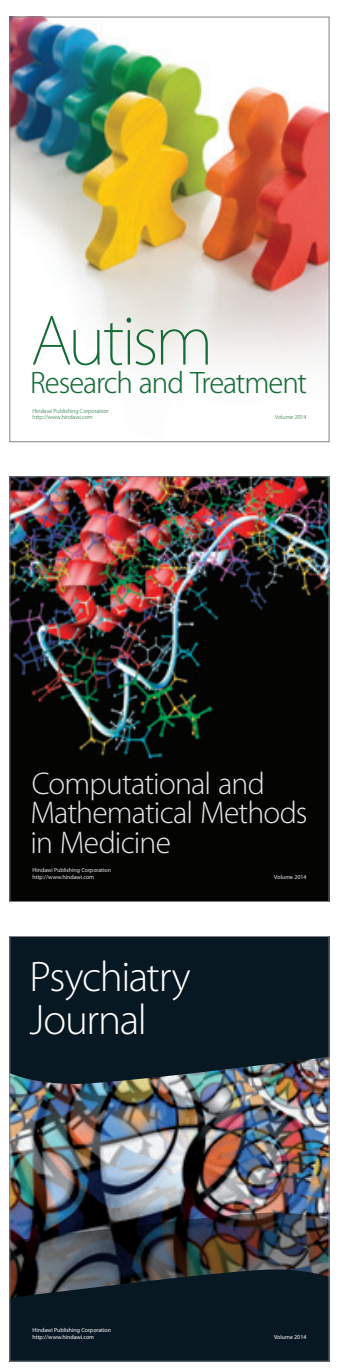
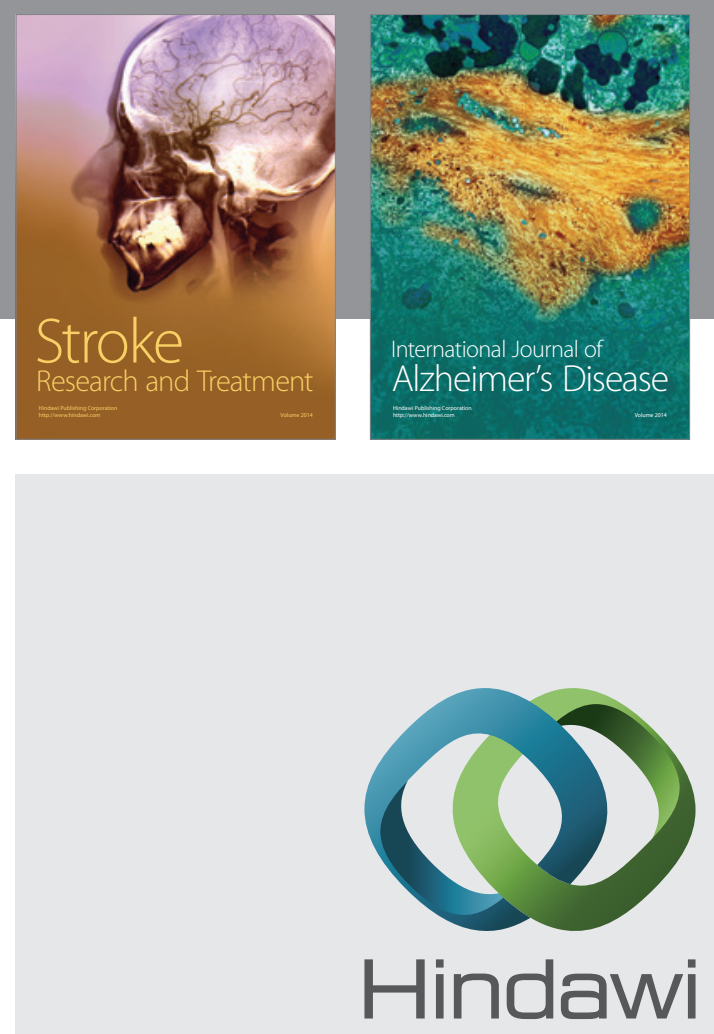

Submit your manuscripts at

http://www.hindawi.com
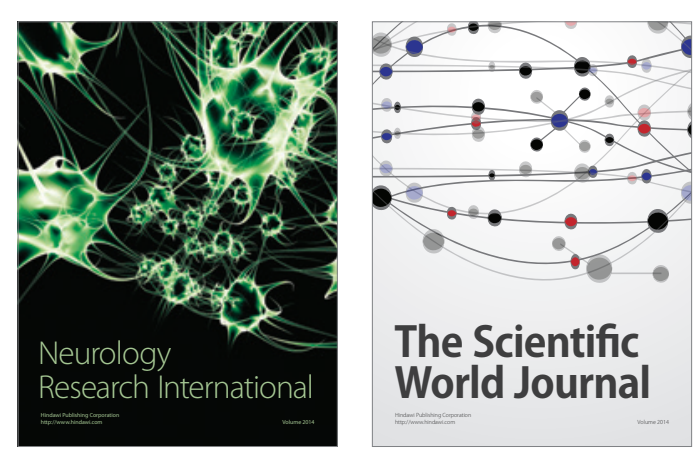

The Scientific World Journal

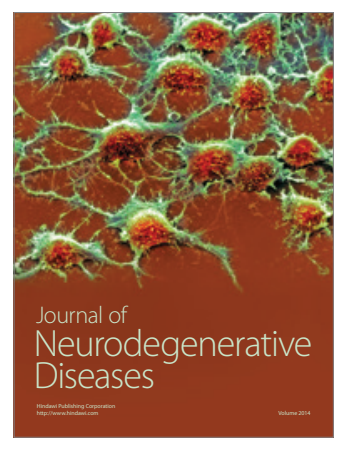

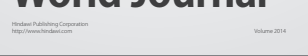

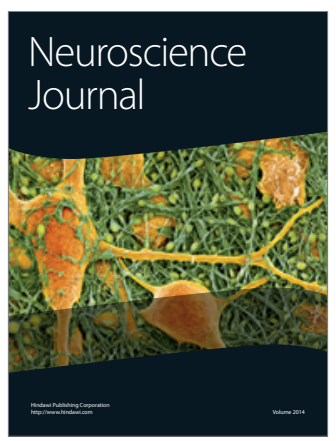

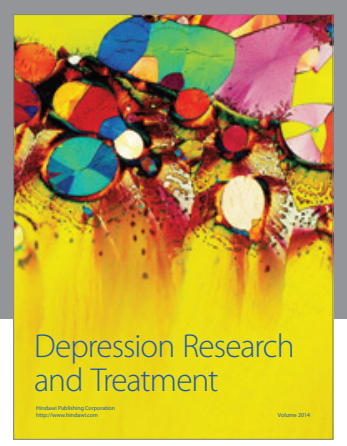
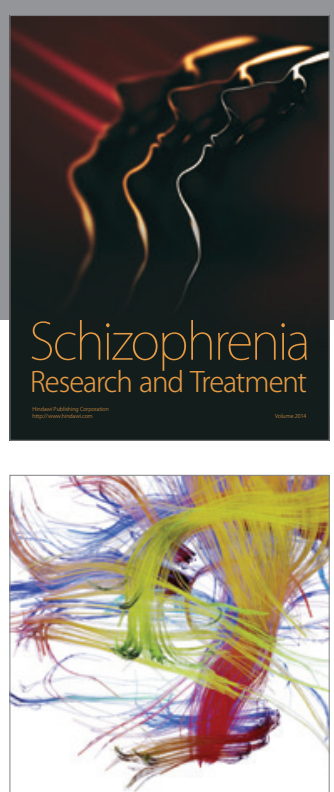

Brain Science

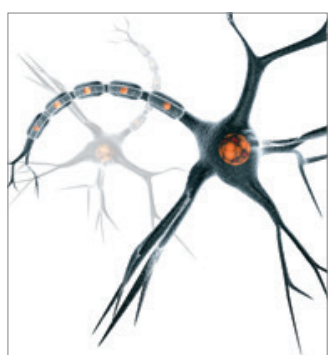

Neural Plasticity
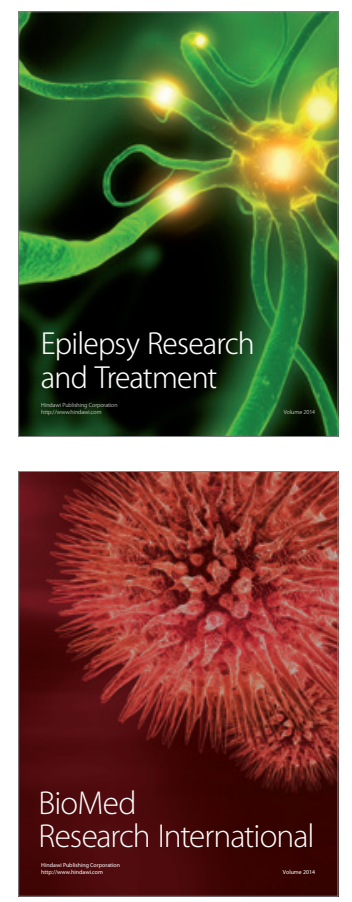

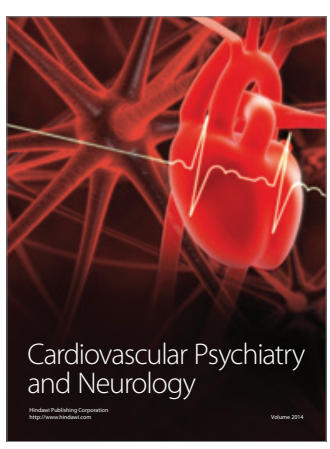

Parkinson's

Disease
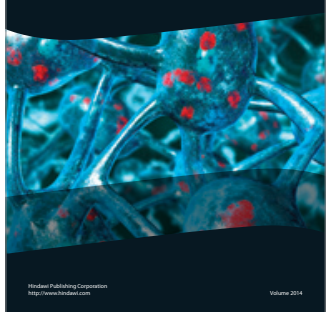